\title{
A Review of Self-healing Metals: Fundamentals, Design Principles and Performance
}

\author{
Shasha Zhang ${ }^{1,2} \cdot$ Niels van Dijk ${ }^{3} \cdot$ Sybrand van der Zwaag ${ }^{4,5}$
}

Received: 19 May 2020 / Revised: 14 June 2020 / Accepted: 16 June 2020 / Published online: 7 July 2020

(c) The Chinese Society for Metals (CSM) and Springer-Verlag GmbH Germany, part of Springer Nature 2020

\begin{abstract}
Self-healing metals possess the capability to autonomously repair structural damage during service. While self-healing concepts remain challenging to be realized in metals and metallic systems due to the small atomic volume of the mobile atoms, the slow diffusion unless at high temperatures and the strong isotropic metallic bonds, the scientific interest has increased sharply and promising progress is obtained. This article provides a comprehensive and updated review on the developments and limitations associated with the various modes of potentially healable damage induced in metals and alloys, i.e., stressinduced damage, irradiation-induced damage in bulk materials and contact damage in corrosion protective coatings. The spontaneous intrinsic healing mechanisms not requiring external assistance other than the material operating at the right temperature and an assisted healing mechanism with external intervention are reviewed. Promising strategies to achieve self-healing in metals are identified. Finally, we give some prospects for future research directions in self-healing metals.
\end{abstract}

Keywords Metal $\cdot$ Self-healing $\cdot$ Creep behavior $\cdot$ Fatigue damage $\cdot$ Irradiation $\cdot$ Coating

\section{Introduction}

Conventionally, metallurgists focus on routes to strengthen metallic materials using mechanisms such as precipitation strengthening, solid solution strengthening and grain size strengthening, in order to suppress the occurrence of internal damage upon the application of an external mechanical

Available online at http://link.springer.com/journal/40195.

Shasha Zhang

s.zhang@nuaa.edu.cn

1 College of Materials and Technology, Nanjing University of Aeronautics and Astronautics, Nanjing 211106, China

2 Key Laboratory of Materials Preparation and Protection for Harsh Environment (Nanjing University of Aeronautics and Astronautics), Ministry of Industry and Information Technology, Nanjing 211106, China

3 Fundamental Aspects of Materials and Energy Group, Faculty of Applied Sciences, Delft University of Technology, Mekelweg 15, 2629 JB Delft, The Netherlands

4 Novel Aerospace Materials Group, Faculty of Aerospace Engineering, Delft University of Technology, Kluyverweg 1, 2629 HS Delft, The Netherlands

5 School of Materials Science and Engineering, Tsinghua University, Beijing 100084, China load. All these concepts find their basis in the implicit use of the "damage prevention" paradigm, and this approach has certainly led to impressive results and many very valuable construction metals with exceptional mechanical properties [1]. However, once the first internal local deformation defects are formed, the performance of the material will drop sharply and the growth of the damage eventually will lead to premature and often unforeseen component failure (Fig. 1). The "damage management" paradigm, creating an in-build capability to repair local damage during service autonomously, provides an alternative strategy to make materials and systems last longer and more reliably. The self-healing mechanisms do not rely on a high strength in the initial stage of service but on the introduction of mobile components, which diffuse to the damage sites. Once the healing agents arrive there, the stress concentration which leads to further damage growth will be removed or reduced. Hence, once localized damage occurs during service, the material exerts a self-healing effect to delay the macroscopic failure, effectively improving the reliability and stability of the metallic components.

Self-healing materials are a type of smart materials that have an autonomous healing ability to damage formed during service. Self-healing materials have made important progress, and research has led to industrial applications of 


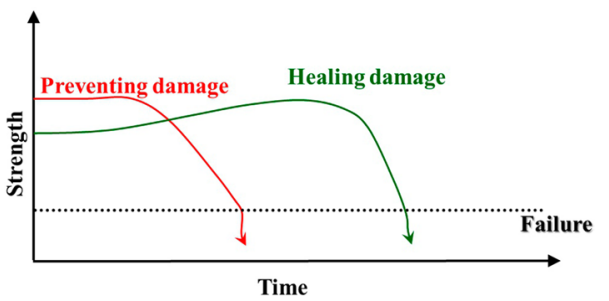

Fig. 1 Schematic comparison of "damage prevention" and "damage healing" mechanisms

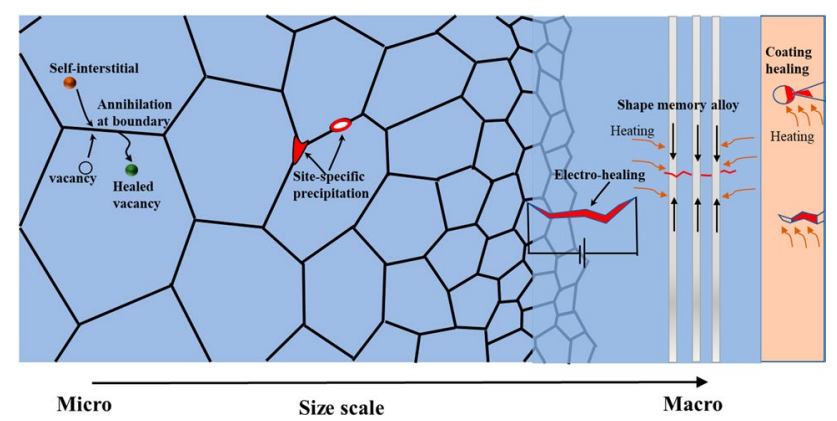

Fig. 2 Schematic overview of the self-healing mechanisms in metallic materials

self-healing polymers [2, 3], self-healing concrete [4] and self-healing ceramics [5]. Realizing a self-healing behavior in metals remains challenging due to the comparatively small volume of individual diffusion atoms in comparison with the critical damage volumes, their slow diffusion and the fact that metals have a high degree of isotropy, i.e., there is no preferred direction in their atomic motion [6-10]. Nevertheless, there has been an increasing interest in self-healing metals in recent years motivated not only by scientific interests but also by the potential high economic benefit when used in real-life applications. In principle, there are two categories of healing mechanisms in metals: autonomous intrinsic healing, which does not require the assistance of external intervention (other than the materials being at a required high temperature to get enough atomic mobility anyway), and assisted healing methods that need an additional (thermal, mechanical, electrical, magnetic or other) external input or trigger to make the healing take place. As shown in Fig. 2, the developed self-healing strategies primarily include site-specific precipitation and boundary/ interface annihilation-based solid-state diffusion at a microscopic scale. Examples of assisted healing are: thermal input for crack closure using shape memory alloys, electrical input to deposit metallic atoms in more macroscopic damage sites, as well as metallic coatings containing microcapsules or low melting temperature solders. Depending on the application, the primary damage categories that self-healing principles are utilized for so far include stress-induced damage and irradiation-induced damage in bulk samples, as well as contact damage in protective metallic coatings. In this review, we will report and critically analyze the progress in selfhealing behavior in different application fields characterized by their damage modes and their healing mechanisms.

\section{Self-healing of Stress-Induced Damage}

\subsection{Site-Specific Precipitation}

In this approach, the mobile atoms diffuse toward the open local damage sites and form new phases therein such that the damage connected with the presence of the cavity is annihilated. "Site-specific" precipitation relies on the presence of supersaturated solutes atoms. However, not every case of supersaturation leads to self-healing. To achieve an efficient intrinsic self-healing by precipitation, the following requirements need to be satisfied $[7,11]$ :

1 A sufficient mobility of the healing agents (solute atoms), i.e., the atoms should diffuse faster than the atoms making up for the metallic matrix;

2 A natural thermodynamic driving force leading the mobile atoms toward the (empty) damage sites;

3 A sufficient amount of healing agents available to fill the collective local damage volume present before the onset of macroscopic failure;

4 Precipitation of the healing atoms only to occur once the damage is formed, in order to keep the atoms in their mobile state and not "consumed" by internal precipitation reactions;

5 A high interfacial bonding between the matrix material surrounding the original cavity and the precipitate formed therein;

6 A sufficiently high healing rate compared to the growth rate of the localized damage.

To realize effective healing within reasonable time, atomic mobility is the key parameter for solid-state intrinsic self-healing in metals, which strongly depends on temperature. As mentioned in a previous paper, the reasonable operation temperature range for intrinsic healing via site-specific precipitation lies in the range $0.40 T_{\mathrm{m}} \leq T_{\text {healing }} \leq 0.65 T_{\mathrm{m}}$, where $T_{\mathrm{m}}$ is the melting point [7]. Application of this temperature window rule for selfhealing in aluminum alloys yields a minimum temperature of $T_{\mathrm{m}} \approx 100^{\circ} \mathrm{C}$, while the minimal temperature for healing in steels is estimated to be $T_{\mathrm{m}} \approx 450^{\circ} \mathrm{C}$. Also the size of the defects that can be healed via diffusional processes can be estimated once the temperature window is defined. It is demonstrated that only microscale damage can be healed via solid-state diffusion, with dimensions smaller than the 
characteristic diffusion length $2 \sqrt{D t}$, where $D$ is the diffusion coefficient and $t$ is the healing time. The size of the damage which can be healed in 1 day is estimated to be in the range from 1.5 to $7 \mu \mathrm{m}$ [7].

Lumley and coworkers studied the creep and fatigue behavior in an $\mathrm{Al}-\mathrm{Cu}-\mathrm{Mg}-\mathrm{Ag}$ model alloy and in AA2XXX aluminum alloys $[9,12,13]$. They found that the presence of solute atoms (in the underaged or supersaturated state) can lead to an increase in creep and fatigue lifetime compared to the peak hardened condition. They proposed that the improved mechanical properties are due to dynamic precipitation at the damage sites. As such, they were the first researchers to propose a self-healing mechanism for the aluminum alloys. Mahdavi Shahri et al. measured the dynamic precipitation process and the defect evolution during fatigue in an AA2024 aluminum alloy in the context of self-healing and found similar phenomena [14]. Hautakangas et al. observed the autonomous healing of strain-induced defects in aluminum alloys via the precipitation of mobile $\mathrm{Cu}$ atoms at the defects with the help of positron annihilation spectroscopy [15]. Michalcova and coworkers discovered the crack-healing phenomenon caused by the precipitation of supersaturated $\mathrm{Ag}$ solutes in $\mathrm{Al}$ [16]. While fruitful research results have been gained in self-healing aluminum alloys, current research is mainly aimed at commonly used heatresistant aluminum alloy systems (AA2XXX series), and the selection of candidate elements for self-healing agents is limited to commonly used alloying elements, such as $\mathrm{Cu}$.

When steels are used under a constant applied stress at elevated temperatures over long periods of time, creep damage takes place. The formation, growth and coalescence of the micro-cavities and cracks at the grain boundaries lead to the formation of macro-cracks resulting in the fracture, which limits the lifetime of the steels and threatens the safety and stability of the steel components. To improve the creep resistance and extend the service lifetime, the self-healing concept provides a new idea to manage small-scale local creep damage formed.

Early previous investigations in the group of Shinya found that B segregation and BN precipitation in conventional stainless steels on the internal surface of the creep cavity provided autonomous healing and creep lifetime extension [17-23]. Copper precipitates also played a role in improving the long-term creep rupture strength of conventional stainless steels [18]. He and coworkers studied the correlation between copper precipitation and deformation-induced defects in Fe-based model alloys and observed the preferential copper precipitation at openvolume defects (dislocations) [24, 25]. Nevertheless, the healing efficiency of solute $\mathrm{Cu}$ is limited since the $\mathrm{Cu}$ precipitates were also found to nucleate uniformly in the $\mathrm{Fe}$ matrix besides the heterogeneous formation at defects.
In later research, the alloying element $\mathrm{Au}$ was chosen as a promising candidate creep damage healing agent for binary $\mathrm{Fe}-X$ alloys, as it meets all the criteria listed above: (1) sufficiently large reservoir of healing agents, i.e., a high solubility in the Fe matrix; (2) high mobility of solute Au [26]; (3) Au precipitation is triggered by damage formation [27, 28]; (4) site-specific precipitation at defect sites [29-31]. The self-healing behavior of stress-induced damage (tensile deformation and creep) by Au precipitation has been studied systematically by Zhang and coworkers [27, 28]. Due to Au having a relatively large atomic size ratio compared to $\mathrm{Fe}$, there exists a high nucleation barrier for $\mathrm{Au}$ precipitation in the iron matrix in the absence of internal open-volume defects. As shown in Fig. 3a, the observations by in situ small-angle neutron scattering indicated that the solute atoms were continuously precipitated in the pre-deformed $\mathrm{Fe}-\mathrm{Au}$ model alloy, whereas no precipitation was observed in the absence of local damage, demonstrating the occurrence of defect-induced precipitation [27]. The mobile gold atoms were found to significantly extend the creep lifetime of iron over that of a binary $\mathrm{Fe}-\mathrm{Cu}$ alloy with a similar excess solute concentration (Fig. 3b) [30]. The microstructural analysis revealed preferential Au precipitation at creep damage sites, resulting in the filling of the damage (partially or fully), as shown in Fig. 3c. Using synchrotron X-ray nano-tomography, the spatial distribution of cavities and precipitates was characterized in $3 \mathrm{D}$ on a nanometer resolution scale and the mechanism of autonomous filling of creep cavities by Au precipitates was further clarified [32]. Figure 3d provides examples of experimentally observed cavities having different filling ratios. The filling ratio should be close to 1 for optimized creep loading conditions (i.e., lower stresses and longer times).

Considering the scarcity and hence high price of gold, the addition of gold as a healing agent in commercial steels is unlikely. Instead, molybdenum (brought in a supersaturated state at the creep loading temperature) has been considered as an alternative healing agent. Autonomous filling of creep cavities at grain boundaries by the $\mathrm{Fe}_{2} \mathrm{Mo}$ Laves phase has been reported [11]. The Fe-Mo system is less effective than the $\mathrm{Fe}-\mathrm{Au}$ system due to a slower diffusivity of the healing agents and a free volume defects being a weaker trigger for site-specific precipitation $[11,26]$. Recently, Fang and coworkers demonstrated a high self-healing potential for $\mathrm{Fe}-\mathrm{W}$ model alloys using advanced synchrotron tomography [33]. Figure 4 demonstrates the spatial correlation between creep cavities and $\mathrm{Fe}_{2} \mathrm{~W}$ precipitates in the $\mathrm{Fe}-\mathrm{W}$ alloy for a time of $0.5 t_{R}$, where $t_{R}$ is the rupture time. It was clearly demonstrated that W-rich Laves phase precipitates formed autonomously in the cavities during creep, always adapting their morphologies to match the remaining open cavity. The healing kinetics was estimated, and different trends were observed 

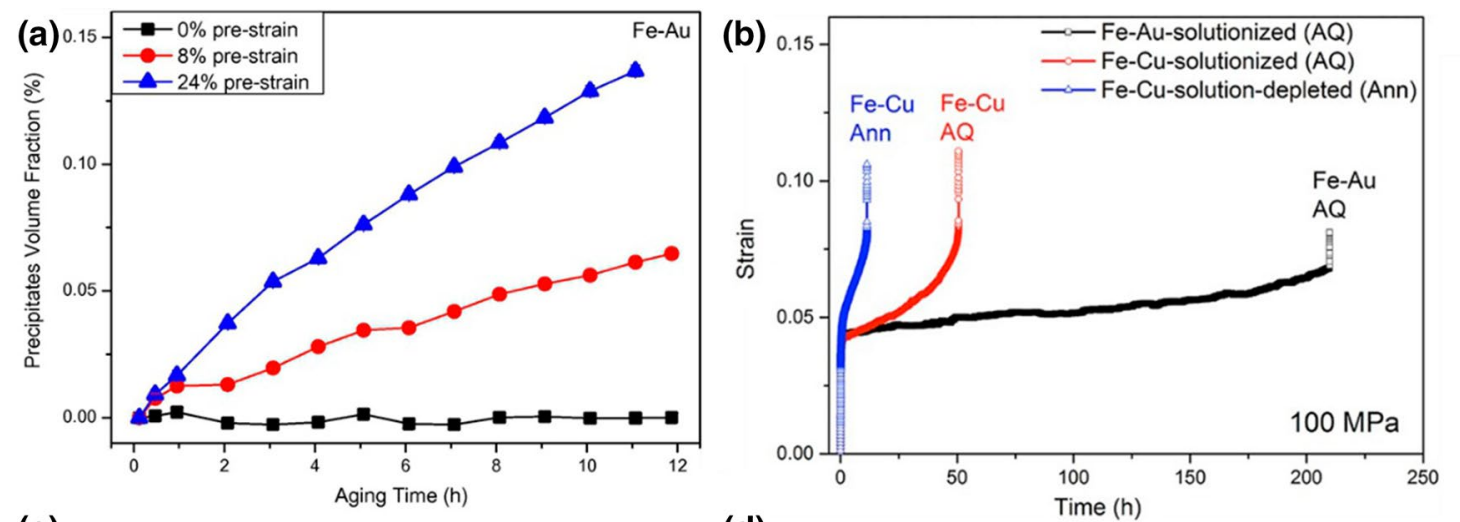

(c)

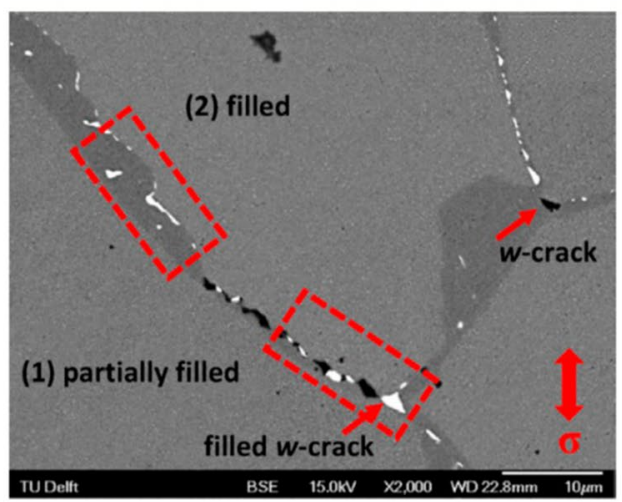

(d)

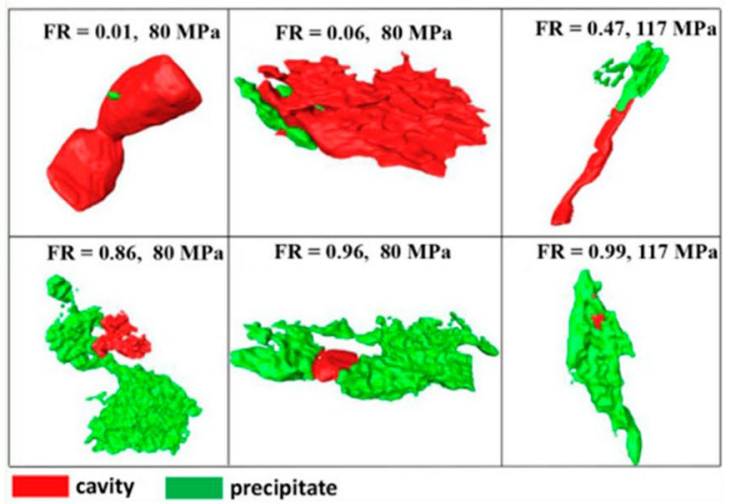

Fig. 3 a Time evolution of the volume fraction of Au-rich precipitates for the Fe-Au alloy with $0 \%, 8 \%$ and $24 \%$ pre-strain during aging at $550{ }^{\circ} \mathrm{C}$; b comparison of the creep curves for the $\mathrm{Fe}-1$ at. $\% \mathrm{Au}$ and $\mathrm{Fe}-1$ at. $\% \mathrm{Cu}$ model alloys $\left(100 \mathrm{MPa}, 550{ }^{\circ} \mathrm{C}\right)$; $\mathbf{c}$ micrograph of filled and partially filled cavities and micro-cracks after creep; $\mathbf{d}$ examples (top view) showing cavities with different filling ratios (FR). Reprinted with permission from Refs. [27, 30, 32]

for the healing and growth rates of isolated and linked cavities. The alloying elements Mo and $\mathrm{W}$ are of particular interest for the design of novel self-healing creep steels as they are also widely used in the design of conventional creep-resistant steels for their solution strengthening and precipitation hardening effects. The self-healing mechanism reported in Fe-Mo and Fe-W provides a new idea to understand the role of solute atoms for the control of creep damage and to design new compositions and treatments to make effect use of the healing potential, while at the same time keeping their strengthening contribution intact.

In addition to extensive experimental studies, computational methods are widely utilized to understand the intrinsic self-healing mechanism of the stress-induced damage and predict the healing efficiency. Wei and coworkers developed a molecular dynamics model to investigate the healing process of nanoscale cracks in iron and found a significant effect of temperature on the healing process $[34,35]$. At room temperature, the mechanism of the crack healing in copper was revealed by dislocation shielding effects with the assistance of atomic diffusion [36, 37]. Wang and coworkers evaluated the crack and void healing in metals using finite element model (FEM) calculations [9].
The self-healing of localized early stage creep damage has also been studied theoretically. Karpov and coworkers investigated the relation between volume diffusion, precipitation and creep cavity growth and studied the dependence of healing dynamics on the applied load and the cavity shape [38]. Using molecular dynamics simulations, the timescale for early healing of the internal nanocrack was evaluated to be within a few picoseconds in nanocrystalline Ni [39]. The healing kinetics was found to be controlled by gain boundary migration and diffusion. Recently, Versteylen and coworkers calculated the evolution of creep damage and precipitation in $\mathrm{Fe}-X$ alloys and compared the self-healing efficiency for $\mathrm{Fe}-\mathrm{Au}, \mathrm{Fe}-\mathrm{Mo}, \mathrm{Fe}-\mathrm{W}$ and $\mathrm{Fe}-\mathrm{Cu}[40,41]$ by combining FEM calculations with ab initio calculations of the solute diffusion coefficients in $\mathrm{Fe}-X$ binary alloys [26].

\subsection{Self-healing Using the Shape Memory Effect and Controlled Heating}

The above-mentioned site-specific precipitation mechanism is mainly used to heal micro-cracks and is unlikely to effectively reduce and control macroscopic damage. An approach to control larger-scale damage is based on making use of 


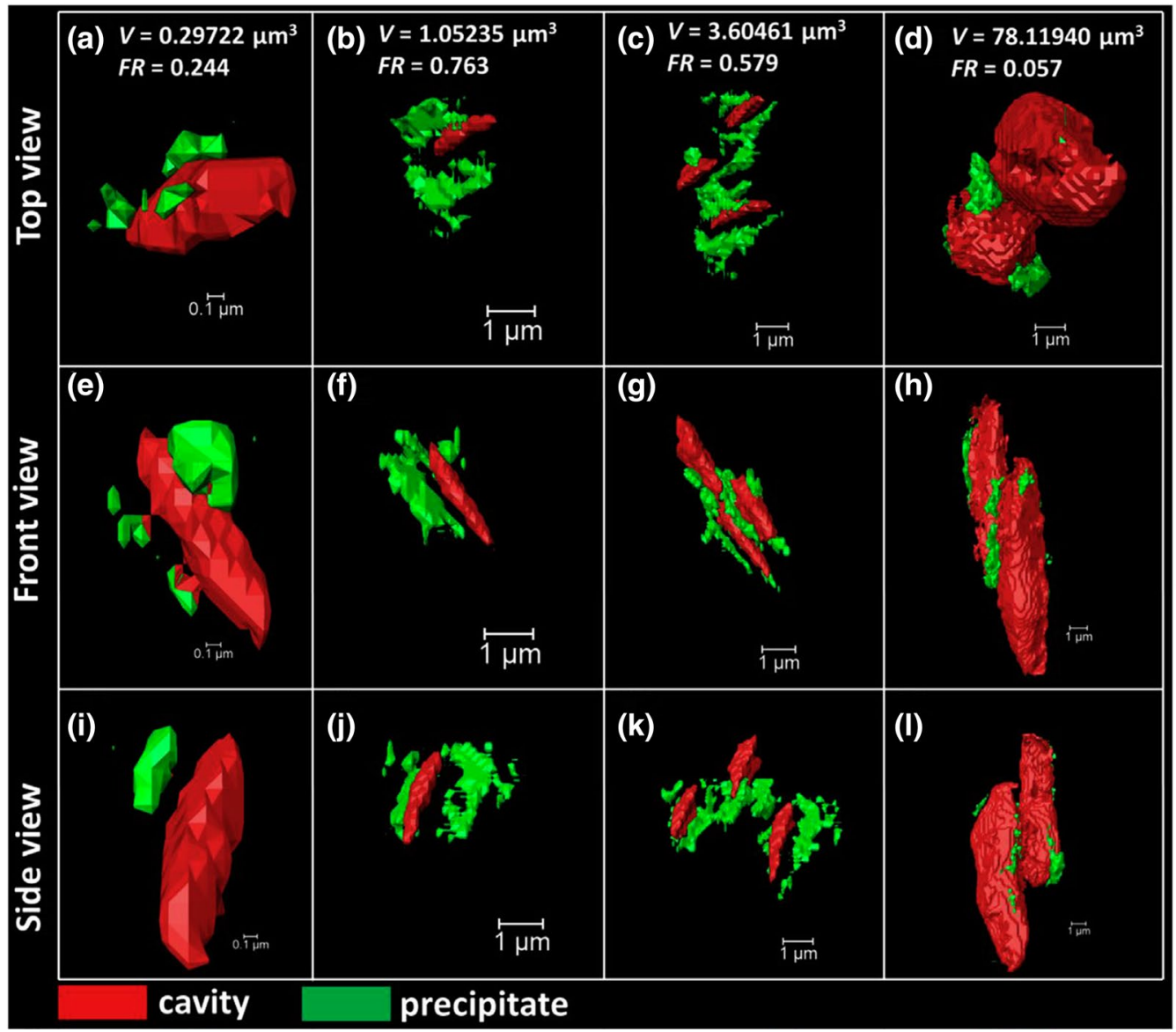

Fig. 4 Examples of partially filled creep cavities in the Fe-W alloy sample after a creep time of $0.50 t_{\mathrm{R}}\left(550{ }^{\circ} \mathrm{C}, 160 \mathrm{MPa}\right)$. The figure shows representations of four partially filled cavities from different angles rendered from high-resolution data with a voxel size of $30 \mathrm{~nm}$. The applied stress is normal to the top view. Reprinted from Ref. [33] with permission from Elsevier

the shape memory effect in embedded shape memory alloy (SMA) wires. To this aim, TiNi fibers were introduced to create self-healing metal-metal composite systems using Sn-, Mg-, Zn- and Al-based alloys as the matrix [42-47]. Figure 5 illustrates the general healing process. Cracks nucleate and propagate in the matrix when a force is applied to the composite. As a result, the SMA reinforcements bridging the crack are stretched. When the composite is heated to a temperature above the reversion temperature of the SMA fibers (and above the actual use temperature at which the damage was formed), a shape recovery is initiated, clamping the crack faces together. Meanwhile, the matrix will soften and/or partially liquefy, leading to crack filling. Using this design principle, Manuel and coworkers realized healing of macro-cracks induced under tensile and fatigue conditions. Over $90 \%$ recovery was achievable for the strength, and the fatigue crack growth was effectively inhibited by the repair process [47]. Additionally, a numerical investigation was conducted to investigate the role of the SMA fibers, the softening behavior of the matrix and the effect of pre-strain in the healing behavior of SMA-reinforced metal matrix composite [48]. Rabkin and coworkers proposed and tested a novel self-healing behavior involving gold microparticles also using shape memory effects [49]. The plastic deformation can be almost fully recovered by annealing at the temperature of $\sim 0.65 T_{\mathrm{m}}$, which was related to fast ledge-guided diffusion. Site-specific crack closure was demonstrated in gold and copper thin films triggered by intrinsic heat release of an exothermic reaction [50]. Kim and coworkers discovered the crack filling phenomena of $\mathrm{Al}-\mathrm{Cu}-\mathrm{Si}$-based alloys enriched with $\mathrm{Sn}$ and Bi during warm rolling. The healing mechanism applied is that of the liquid phase separation alloy design principle [51].

\subsection{Electro-healing}

Besides thermal input as external driving for healing, electrical fields have also been utilized to promote the healing process especially for macroscopic damage. Shi and coworkers provided a novel electro-healing approach, and cracks in the micrometer range were successfully healed by an electrochemical process, where metallic 


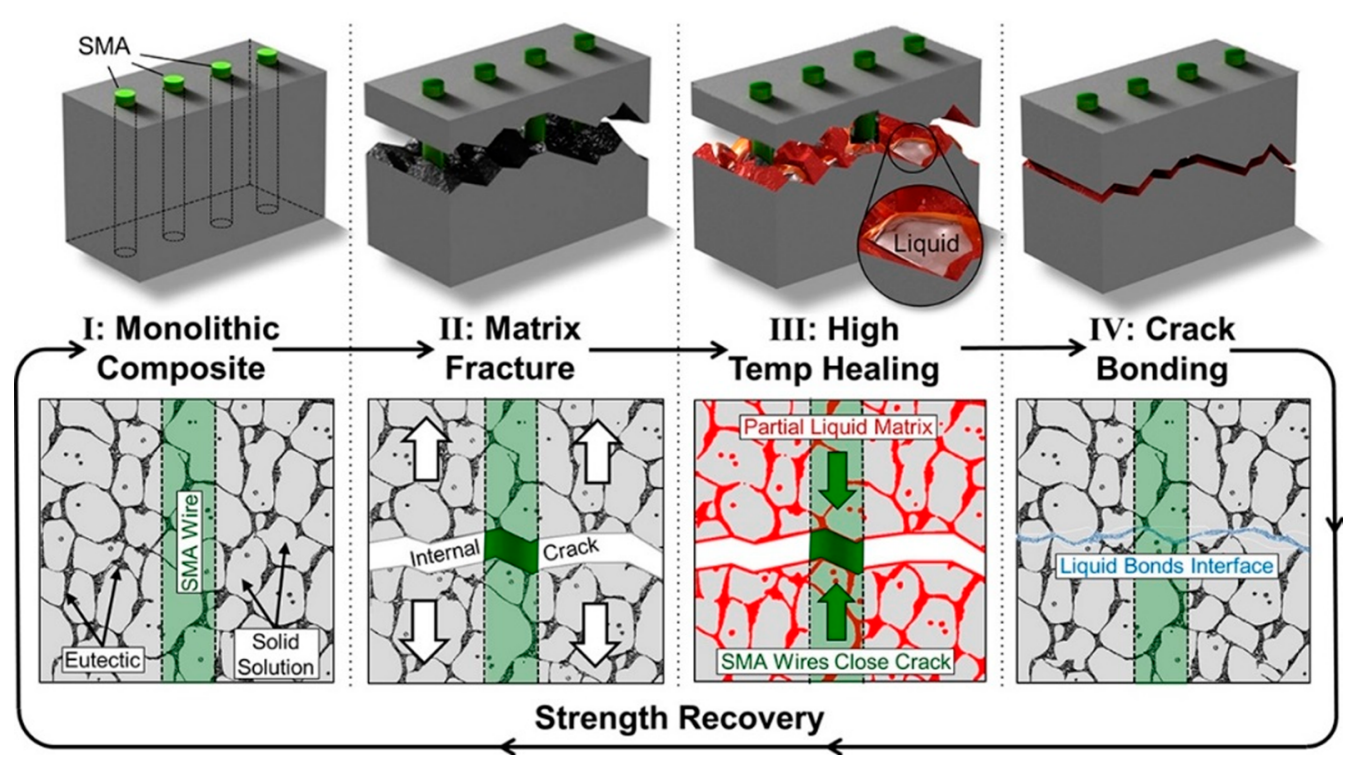

Fig. 5 Schematic diagram of a shape memory alloy self-healing system. Reprinted with permission from Ref. [47]

ions in the electrolyte were used as healing agents [52]. After healing, the tensile strength can be fully maintained, whereas a partial recovery of the ductility was observed, as shown in Fig. 6. Using cathodic electrophoretic deposition, healing of large-scale cracks $(30 \mu \mathrm{m})$ in metalloceramic MAX phase has also been realized [53]. Recently, Hsain and Pikul developed a low-energy and room-temperature healing approach of cellular metals, which mimicked the bone healing. When the polymercoated cellular nickel was immersed into an external electrolyte, electrochemical reactions transported nickel ions from the anode to the fractured areas, resulting in an effective recovery of mechanical properties, as shown in Fig. 7 [54]. Wang et al. applied electropulsing as extrinsic energy to heal the microcrack via a process of currents redistribution, which resulted in a thermal and compressive stress concentration around crack, driving atom flow to close cracks tips $[55,56]$. Here, the micro-cracks acted as the trigger to activate the healing process.

In addition to structural applications of the electrohealing, the self-healing approach is also being studied for solders, submicron aluminum and nanocrystalline gold interconnectors to solve the electromigration problems, the significance of which increases notably as the size of integrated circuit decreases [57-61]. Electrical testing showed that cracks formed due to electromigration can disappear upon the application of a high-density current of the right duration. The closure of the cracks was the result of electro-migrative mass diffusion.

\section{Self-healing of Radiation Damage}

Metallic materials are crucial in nuclear energy installations [62]. They are designed to withstand conditions in hazardous nuclear environments, including high temperatures, high stresses, strong radiation and corrosion. Besides creep and corrosion damage, various forms of high-density radiation damage such as vacancy clusters, dislocation loops and networks, voids, bubbles and stacking fault tetrahedra (SFTs) are inevitably formed during service, which significantly undermine the mechanical properties of the structural alloys. Due to the fact that most components in the reactor are difficult or even impossible to repair or replace, the lifetime and service reliability of the materials directly determine the service life of nuclear reactors. The self-healing mechanism provides a novel approach to manage the radiation damage and extend the component lifetime, thereby improving the safety and application effectiveness of nuclear power systems.

A well-developed strategy to realize self-healing of radiation damage is to manipulate the composition and structure of boundaries and interfaces, which both act as defects sinks. Researchers at Los Alamos National Laboratory (LANL) discovered the "loading-unloading" effect of grain boundaries in copper and firstly proposed the selfhealing mechanism of the radiation-induced damage using atomic simulation methods [63]. Borovikov et al. proposed that in pure tungsten the coupled grain boundary motion 

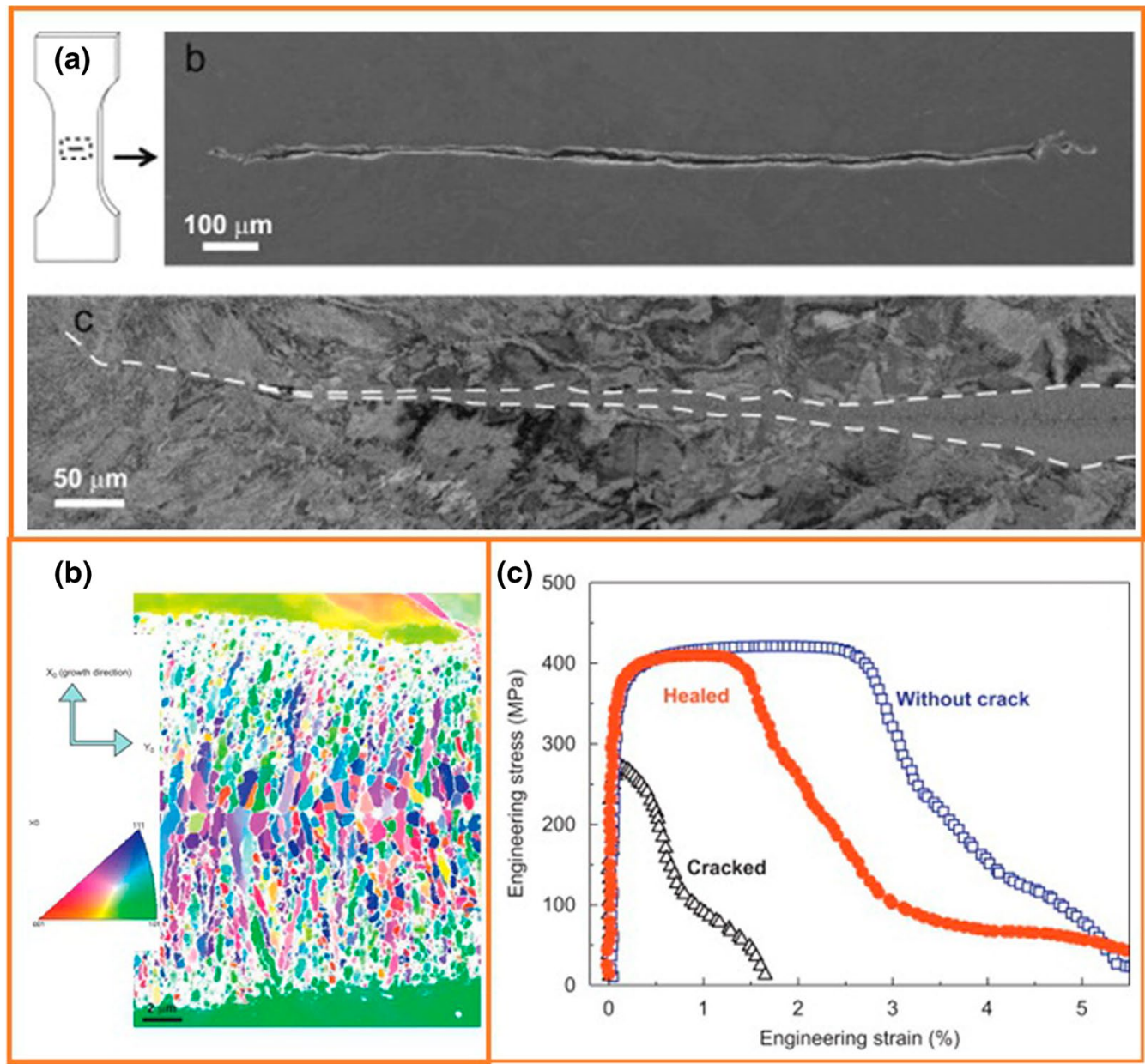

Fig. 6 a SEM image of the crack before and after healing in nickel; b electron backscatter diffraction (EBSD) image of the central part of the healed crack; c tensile stress-strain curves of the sample without crack and the cracked samples with and without healing process. Reprinted with permission from Ref. [52]

can sweep up the defects, i.e., voids and vacancies, leading to a radiation-damage healing mechanism [64]. This phenomenon is similar to the self-healing mechanism of nanocracks induced by shear stress via grain boundary motion, generating disclinations [65]. Liu and coworkers calculated the radiation resistance of nanocrystalline $\mathrm{Fe}$ and confirmed the assumed annihilation phenomenon of interstitials and vacancies near the grain boundaries [66]. Ackland anticipated that the self-healing mechanism provided a way to control radiation damage through tuning of the grain boundaries, which may render nanomaterials that are highly useful for nuclear applications [67]. However, the small grain size is assumed to be detrimental for the creep resistance, which is an equally important property for structural nuclear materials. Direct experimental evidence to prove the autonomous healing effect of the grain boundaries is urgently required.

Zhang and coworkers observed the self-healing behavior of twin boundaries during the in situ study of the defect migration for nanotwinned silver under $\mathrm{Kr}$ ion irradiation [68]. Figure 8 illustrates the interactions between dislocation loops and twin boundaries. At the first stage, an initially straight coherent twin boundary (CTB) captured a mobile interstitial loop, resulting in a distortion. Subsequently, vacancy clusters were formed near the twin boundary, which prompted the interstitial defects to redistribute along the boundary. The annihilation of interstitials with vacancy clusters led to the self-healing of the CTB. Li and coworkers found that the dispersion of carbon nanotubes in aluminum can also improve the radiation resistance due to the self-healing effect at the filler-metal interfaces, where the vacancies recombine with the self-interstitial atoms [69]. The features of the boundaries/interfaces are the key factor for healing the defects. The geometry change for the boundaries/interfaces, induced by the stress field of interstitial loop, guarantees active engagement and removal of the defects clusters. Moreover, the rapid transportation along the boundaries/interfaces increases the possibility for the 

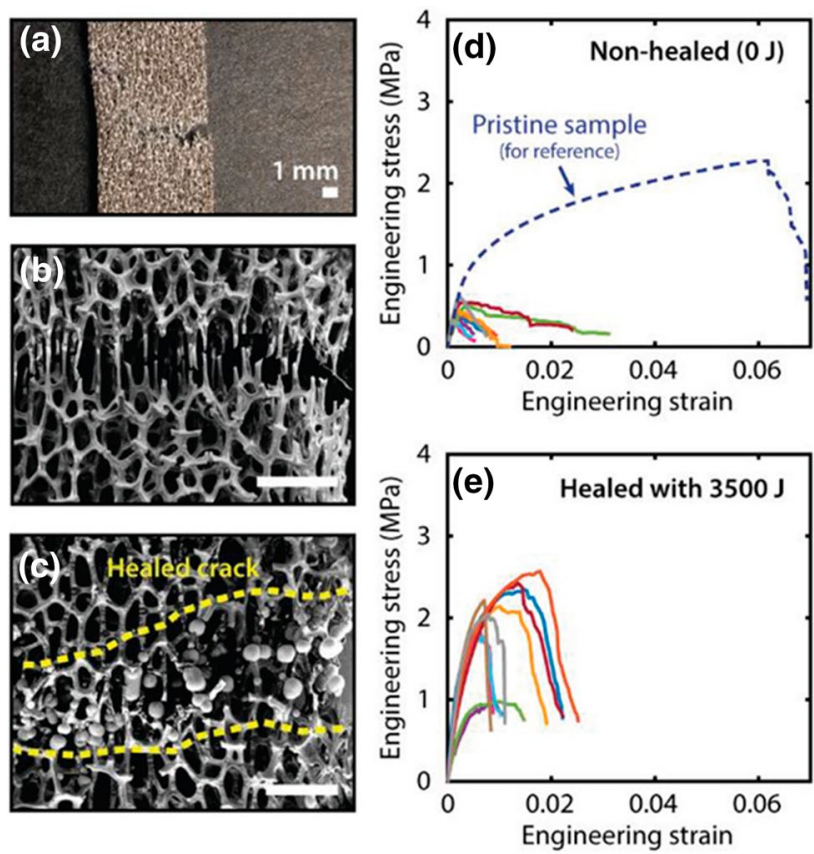

Fig. 7 Healing of cellular nickel subjected to tensile loading near failure, the photograph and SEM micrograph and stress-strain data of samples before and after healing. Reprinted with permission from Ref. [54]

annihilation of interstitials and vacancies, facilitating the self-healing process.

Recently, a similar annealing effect was observed in metallic glasses (MGs), which are a special class of metallic materials. Liang et al. investigated the structural evolution of amorphous $\mathrm{ZrCu}$ binary alloys and found that the vacancy-like defects induced by neutron irradiation were fully annihilated after a structure relaxation by the rearrangement of free volume, demonstrating the self-healing effect. Moreover, the free volume rearrangement strongly depended on the constituent elements, which implied that the composition design was essential to realize the self-healing mechanism [70]. This group further discovered the self-healing of irradiation-induced vacancies in amorphous-nanocrystalline $\mathrm{ZrCu}$ alloy. As shown in Fig. 9, the phase boundary between the nanocrystal and the amorphous structure tended to move toward the crystal zone upon annealing. Once the vacancies connected with the phase boundary, they instantaneously and totally annihilated. Interestingly, when all the vacancies nearby were annihilated, the phase boundary would no longer move toward the crystalline regions, but change the direction of its motion toward the amorphous region, demonstrating a strong damage response $[71,72]$.

Inspired by the work on self-healing of creep damage in Fe-based alloys, Zhang and coworkers have evaluated the self-healing potential of solute $\mathrm{Cu}$ and $\mathrm{Au}$ in $\mathrm{Fe}$ for radiation damage [73-75]. Under irradiation $\left(550{ }^{\circ} \mathrm{C}, \mathrm{He}^{+}\right)$, site-specific Au precipitation at defect sites was observed (Fig. 10a), whereas only a weak spatial correlation was found between the $\mathrm{Cu}$ precipitates formed and the regions of radiation damage (Fig. 10b). The autonomous healing of the defects by damage site-specific Au precipitation resulted in a reduced radiation swelling compared to that in the $\mathrm{Fe}-\mathrm{Cu}$ alloy (Fig. 10c). Ab initio calculations unraveled the origin of the difference in the correlation between $\mathrm{Au} / \mathrm{Cu}$ solutes and defects, i.e., the binding energies of Au solutes to irradiation-induced defects were shown to be significantly higher than those of solute $\mathrm{Cu}$ atoms (Fig. 10d).

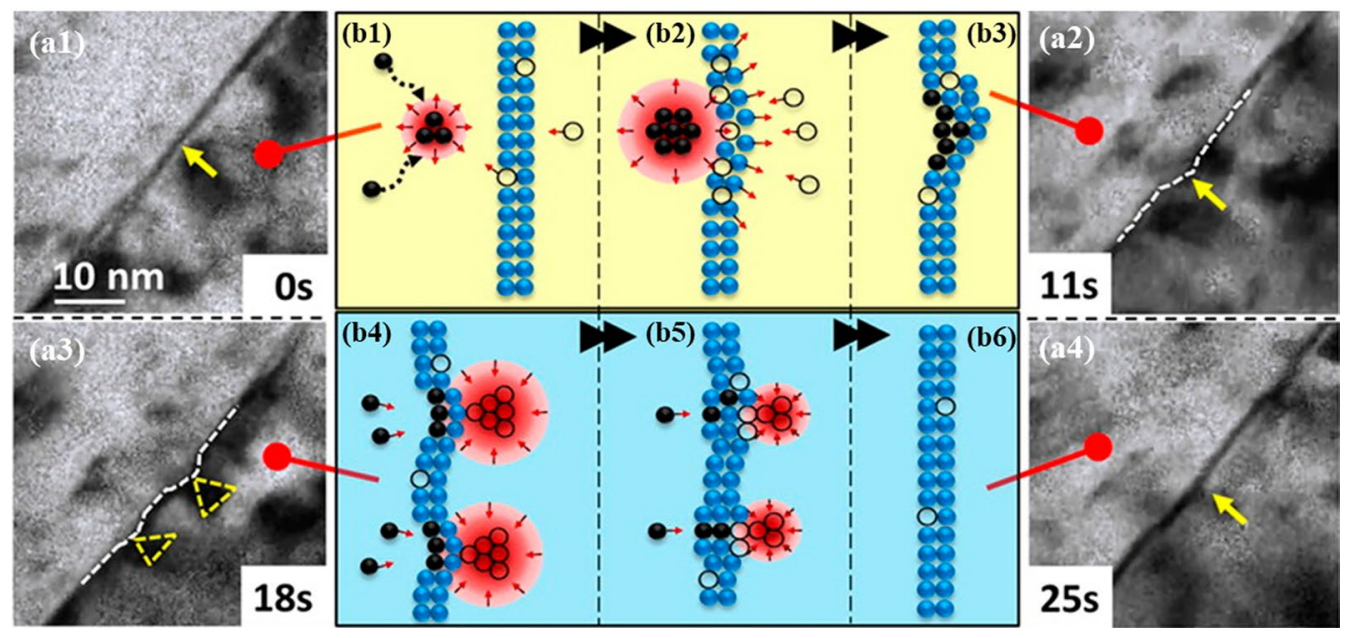

Fig. 8 Distortion and self-healing of coherent twin boundaries (CTBs). An initially straight CTB a1 formed a curved puddle upon its encountering of a mobile interstitial loop a2. The puddle on CTB was replaced by two undulations a3. By $25 \mathrm{~s} \mathbf{a} 4$, the CTB was nearly recovered (selfhealed). b1-b6 Schematics illustrate the capturing of defect clusters by CTB and their self-healing mechanism. Reproduced with permission from Ref. [68]. Copyright (2015) American Chemical Society 

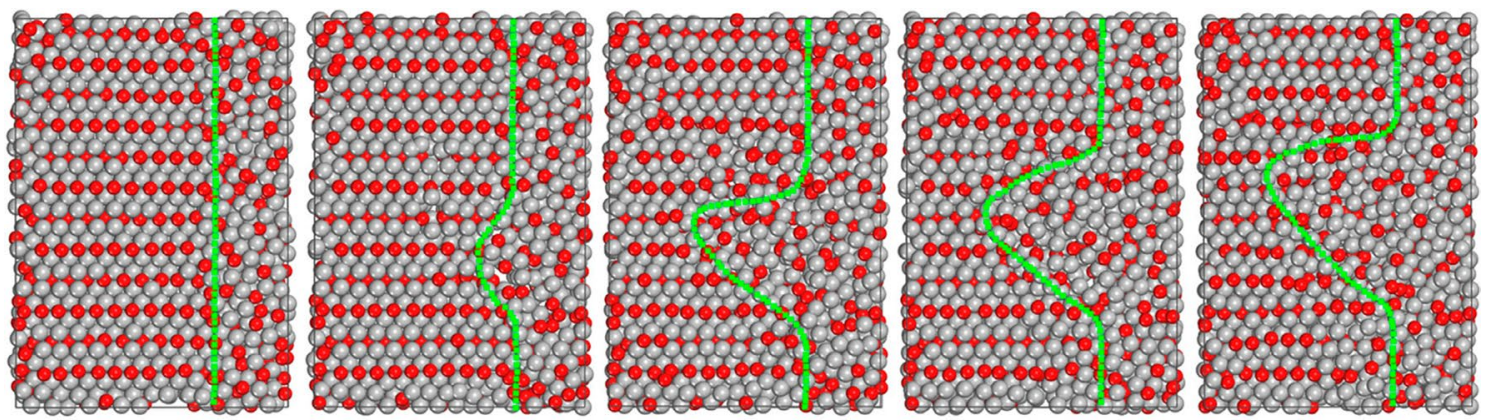

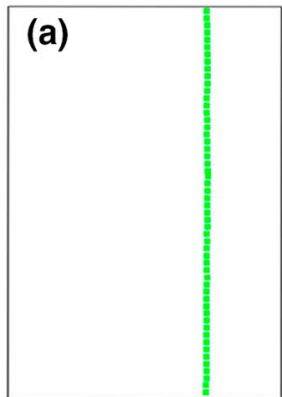

(b)
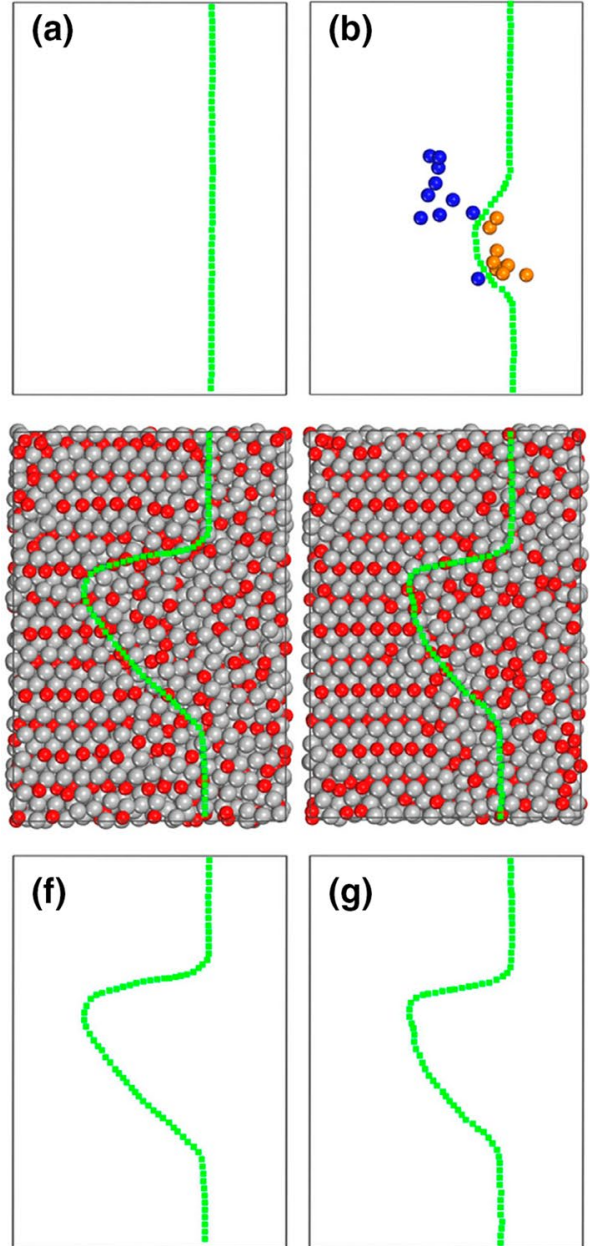

(c)
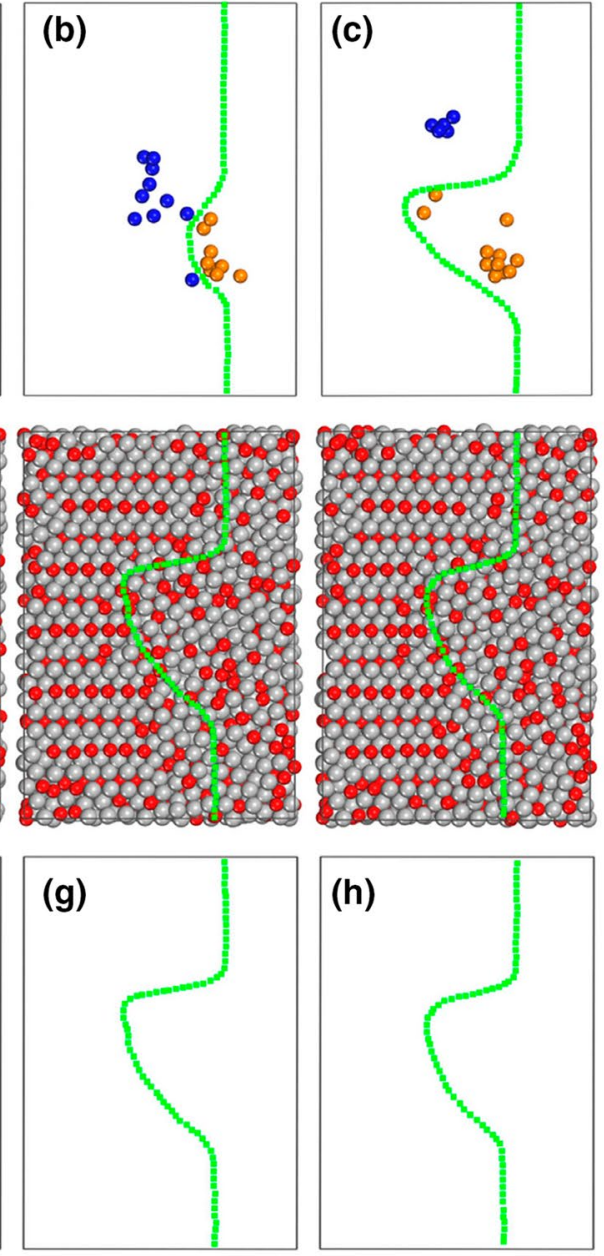

(d)

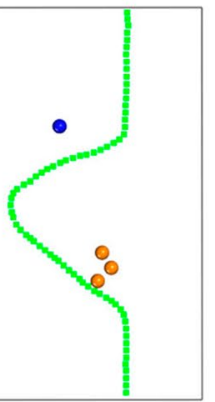

(e)

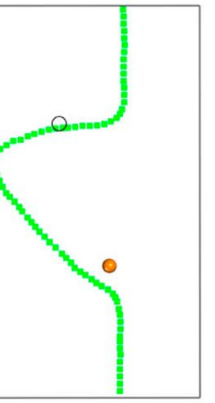

(i)

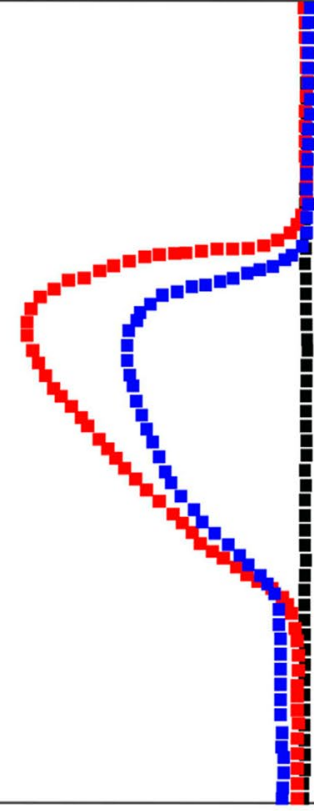

Fig. 9 Evolution of the amorphous-crystal phase boundaries and the irradiation-induced vacancies (blue spheres) in nanocrystal grain and vacancy-like defects (brown spheres) in amorphous matrix, of the intercepted ANA model. Various snapshots of this model are shown, at the simulation time of a $0.0 \mathrm{ps}, \mathbf{b} 0.2 \mathrm{ps}, \mathbf{c} 0.4 \mathrm{ps}, \mathbf{d} 0.6 \mathrm{ps}, \mathbf{e} 0.8 \mathrm{ps}, \mathbf{f} 1.3 \mathrm{ps}, \mathbf{g} 4.0 \mathrm{~ns}, \mathbf{h} 20.0 \mathrm{~ns}$. i The black, the red and the blue lines denote the phase boundaries at the simulation time of $0.0 \mathrm{ps}, 0.8 \mathrm{ps}$ and $20.0 \mathrm{~ns}$, respectively. Reprinted from Ref. [71] with permission from Elsevier

\section{Self-healing Metallic Coatings}

Coatings are susceptible to damage in the form of localized contact damage leading to the formation of cracks, pits, craters, etc., which leads to localized failure of the coating and subsequent degradation of the underlying substrate. Major advances for autonomous repair of defects have been made in the field of smart coatings with embedded microcapsules
[76]. Once damage occurs in the coating matrix, the healing agents will be released from the capsules and "wet" the crack opening. While self-healing coatings with microcapsules are now well known in the field of organic coatings, this self-healing strategy can in principle also be applied in metallic coatings. Alexandridou and coworkers firstly reported the synthesis of microcapsules embedded in $\mathrm{Ni}$ based composite coatings using electrodeposition [77]. 
(a)
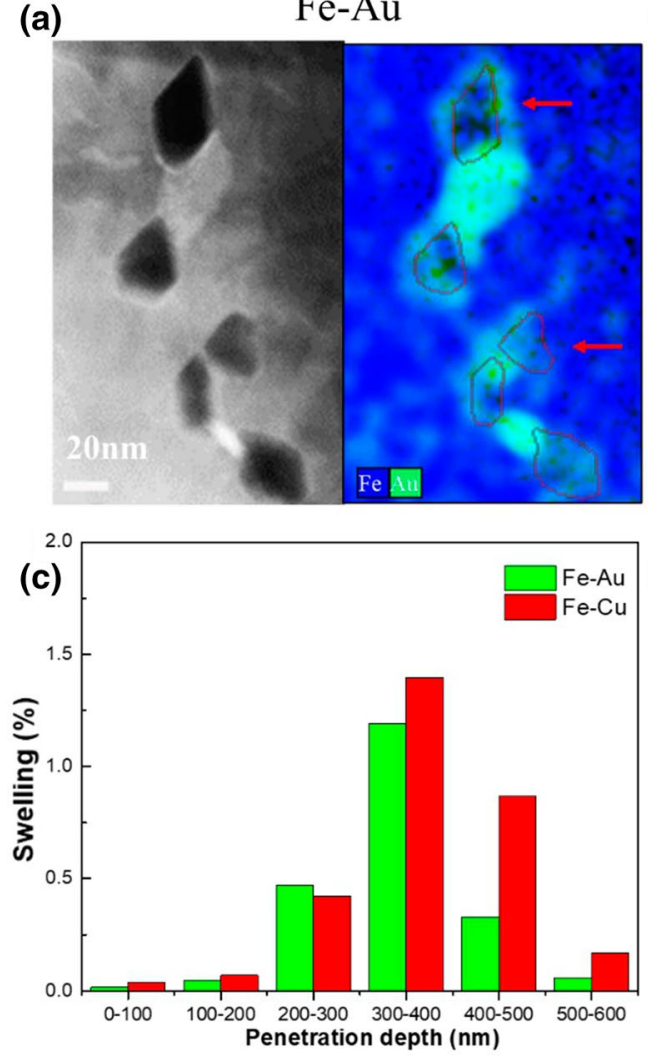

(b)

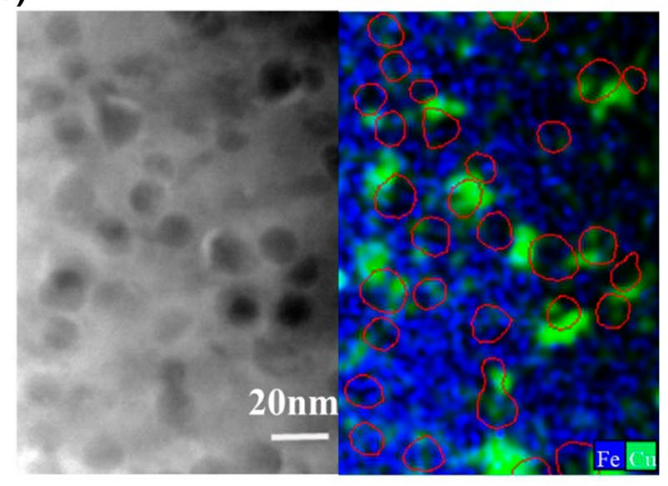

(d)

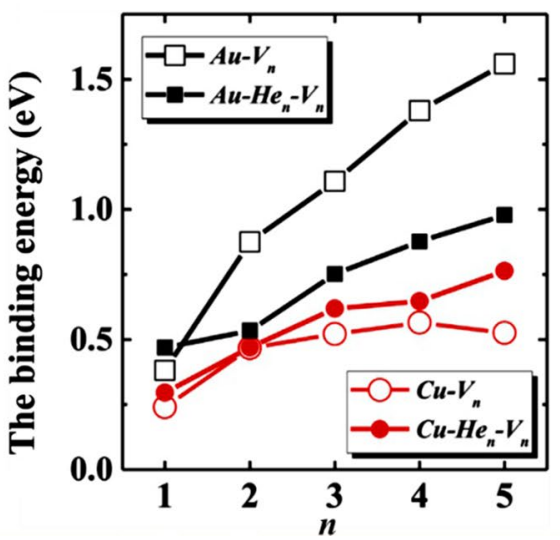

Fig. 10 HAADF mode TEM image of the $\mathrm{Fe}-\mathrm{Au}$ alloy $\mathbf{a}$ and the $\mathrm{Fe}-\mathrm{Cu}$ alloy $\mathbf{b}$ with corresponding elemental mapping after $\mathrm{He}^{+}$irradiation $\left(550{ }^{\circ} \mathrm{C}, 1.27 \mathrm{dpa}\right)$; c comparison of radiation swelling along the projected radiation depth for the irradiated $\mathrm{Fe}-\mathrm{Au}$ ad $\mathrm{Fe}-\mathrm{Cu}$ alloys; $\mathbf{d}$ binding energies of complexes $\mathrm{Au}-V_{n}\left(E_{\mathrm{b}}^{\mathrm{Au}-V_{n}}\right), \mathrm{Cu}-V_{n}\left(E_{\mathrm{b}}^{\mathrm{Cu}-V_{n}}\right), \mathrm{Au}-\mathrm{He}_{n} V_{n}\left(E_{\mathrm{b}}^{\mathrm{Au}-\mathrm{He}_{n} V_{n}}\right)$ and $\mathrm{Cu}-\mathrm{He}_{n} V_{n}\left(E_{\mathrm{b}}^{\mathrm{Cu}-\mathrm{He} V_{n}}\right)$ plotted as a function of the vacancy cluster size $n$. Reprinted from Refs. [73, 74] with permission from Elsevier

Later, Ni- and Cu-based coatings with shelled microcapsules were developed [78, 79]. The release of the content of the microcapsules could be triggered by a local $\mathrm{pH}$ change or by another internal stimulus activated by the onset of corrosion. The resulting healing reaction improved the overall corrosion resistance.

An alternative approach to realize autonomous healing is by covering the surface of a metallic object with a low melting temperature solder. When a crack is formed in the substrate, upon heating component the film will melt and infiltrate the crack opening due to capillary forces. The healing material inhibits further crack growth by bridging the crack faces. Leser and coworkers demonstrated the principle by depositing a thin layer of solder (In-Sn) as the healing material on a titanium alloy substrate [80]. The steady-state fatigue crack growth rate was reported to have been significantly inhibited by introducing a healing treatment once the early fatigue cracks were formed $\left(135^{\circ} \mathrm{C}, 1 \mathrm{~h}\right)$. X-ray computed tomography (CT) characterization, with complementary energy-dispersive spectroscopy (EDS) analysis, confirmed that the healing agent indium and tin had covered the crack surface. Beside solder powders, metal nanoparticles
[81] and planar metal oxides [82] can also act as self-healing agents in coatings.

\section{Conclusions and Prospects}

In this paper, we have reviewed the research status and developments in self-healing metals. Self-healing concepts have been developed using various mechanisms. The healing of the most promising damage types, i.e., stress-induced cracks and cavities, radiation damage and local contact damage are analyzed in detail. In the case of internal damage in components operating at high temperatures, intrinsic healing via solid-state diffusion was shown to work very well. In examples of extrinsic healing, an additional processing step is usually required, but also then good results have been obtained.

While these strategies are demonstrated to be feasible to realize self-healing behavior in metals, most studies still belong to the proof-of-principle stage. The following research directions are suggested for the development 
of future self-healing metals suitable for commercial applications.

1 Self-healing concepts coupled with damage prevention strategy.

The synergistic effect of the damage prevention mechanisms and the self-healing mechanisms is expected to achieve a simultaneous increase in strength and lifetime. Taking selfhealing steels as an example, the self-healing mechanism of creep damage by precipitation is demonstrated to be highly promising in Fe-based binary alloys. To realize commercial application, it is advised to incorporate self-healing agents in commercial creep-resistant steels, so that potential commercial benefits of extending safe lifetimes are gained due to self-healing together with the damage prevention ability guaranteed via the strengthening mechanism. To achieve synergistic effects, advanced computational methods are essential to design the optimal compositions and heat-treatment routes [83, 84].

1 New healing agents and other metallic systems.

So far, intrinsic self-healing phenomena have been explored for aluminum alloys and steels. The candidate elements investigated as self-healing agents include $\mathrm{B}, \mathrm{N}, \mathrm{Cu}, \mathrm{Au}$, $\mathrm{Mo}$ and $\mathrm{W}$ for Fe-based alloys and $\mathrm{Cu}, \mathrm{Mg}$ and $\mathrm{Ag}$ for aluminum-based alloys. Most of the chosen self-healing agents primarily belong to common alloying elements, but special concentrations and pretreatments are required to get the metal in the correct microstructural state for the later activation of the healing process. Guided by the "damage management" paradigm, we may search for new alloying members with a high self-healing potential. To achieve this purpose, computational simulations will play an important role in predicting the interaction between damage and healing agents not only for binary and ternary model systems but also for multicomponent alloys. Furthermore, the self-healing approach should also be explored for other alloys than Fe- and Al-based systems. For example, Lee and coworkers observed a similar self-healing behavior in nickel-based alloys (Inconel 617B) [85]. They found that micro-cracks were autonomous filled with $M_{23} C_{6}$ precipitates with additional segregation of $\mathrm{B}, \mathrm{C}$ and $\mathrm{S}$, resulting in a larger elongation at break and a higher creep strength.

\section{Interdisciplinary studies.}

Interdisciplinary studies are essential to develop new strategies in order to realize self-healing and new application for self-healing metallic materials. For instance, the studies on self-healing nuclear materials, bringing together materials science and nuclear engineering, have revealed the sink function of grain/twin boundaries and interfaces, which act as annihilation sites for irradiation-induced defects, as a new type of healing mechanism. On the other hand, the self-healing strategy in nuclear materials paved the way for a new method to control radiation damage. Balazs and coworkers designed a synthetic repair system and found that nanomotors (Au/Pt Janus particles) can autonomously detect and repair microscopic cracks to restore the electricity of broken electronic pathways [86]. The rapid healing of $\mathrm{Au} / \mathrm{Cu}$ films was achieved for on-chip microelectronic components with the thermal trigger supplied by an intrinsic solid-state reaction [50]. Future interdisciplinary studies, combining materials science with automation engineering and/or electronic technology, are expected to bring new possibilities to the field of self-healing in metals.

With the development of computational science, modeling strategies are expected to play an increasing role in the study of self-healing in metals for unraveling the mechanism behind the healing phenomena, anticipating the healing efficiency and designing new self-healing systems. Generally, finite element model (FEM) calculations are employed to simulate the healing effect on microscopic cracks, whereas molecular dynamics (MD) methods are utilized to model the time evolution of nanoscale defects. In some cases, multiscale modeling combining methods with different length scales is employed to unravel the healing mechanism [38, 66]. In principle, a truly informative model should be able to model the topology and the kinetics of the damage formation as well as that of the healing reaction. For example, Ponnusami and coworkers developed a cohesive-zone crackhealing model, which modeled both the damage evolution and the properties after (single or even multiple) healing of a thermal barrier coating containing discrete healing particles [87]. In general, micromechanics and/or phase field models are the two most appropriate models to consider, as they can address both the kinetic and topological aspects of damage and healing. Both models require values for a range of model parameters, but with some calibrations these models become semi-predictive.

Acknowledgements This work was financially supported by the National Natural Science Foundation of China (Grant No. 51701095) and the Natural Science Foundation of Jiangsu Province, China (Grant No. BK20170798).

\section{References}

[1] S. Zwaag, Self-healing Materials (Springer, Dordrecht, 2008)

[2] S.R. White, N. Sottos, P. Geubelle, J. Moore, M.R. Kessler, S. Sriram, E. Brown, S. Viswanathan, Nature 409, 794 (2001)

[3] Y. Yang, J. He, Q. Li, L. Gao, J. Hu, R. Zeng, J. Qin, S.X. Wang, Q. Wang, Nat. Nanotechnol. 14, 151 (2019)

[4] V. Wiktor, H.M. Jonkers, Cem. Concr. Compos. 33, 763 (2011) 
[5] W.G. Sloof, R. Pei, S.A. McDonald, J.L. Fife, L. Shen, L. Boatemaa, A.S. Farle, K. Yan, X. Zhang, S. van der Zwaag, Sci. Rep. 6, 23040 (2016)

[6] M.D. Hager, P. Greil, C. Leyens, S. van der Zwaag, U.S. Schubert, Adv. Mater. 22, 5424 (2010)

[7] N. van Dijk, S. van der Zwaag, Adv. Mater. Interfaces 5, $1800226(2018)$

[8] B. Grabowski, C.C. Tasan, Self-healing Metals (Springer, Berlin, 2016), pp. 387-407

[9] S. van der Zwaag, Self Healing Materials: An Alternative to 20 Centuries of Materials Science (Springer, Dordrecht, 2008)

[10] S. van der Zwaag, E. Brinkman, in Self Healing Materials: Pioneering Research in the Netherlands, (Netherlands, 2015)

[11] S. Zhang, H. Fang, M. Gramsma, C. Kwakernaak, W. Sloof, F. Tichelaar, M. Kuzmina, M. Herbig, D. Raabe, E. Brück, Metall. Mater. Trans. A 47, 4831 (2016)

[12] R.N. Lumley, A.J. Morton, I.J. Polmear, Acta Mater. 50, 3597 (2002)

[13] R. Lumley, R.G. O’Donnell, I.J. Polmear, J.R. Griffiths, Mater. Mater. Forum 29, 256 (2005)

[14] M. Mahdavi Shahri, R.C. Alderliesten, S. van der Zwaag, H. Schut, Advanced Materials Research (Trans Tech Publ, Zürich, 2014)

[15] S. Hautakangas, H. Schut, N.H. van Dijk, P.E.J. Rivera Díaz del Castillo, S. van der Zwaag, Scr. Mater. 58, 719 (2008)

[16] A. Michalcová, I. Marek, A. Knaislová, Z. Sofer, D. Vojtěch, Materials (Basel) 11, 199 (2018)

[17] K. Laha, J. Kyono, S. Kishimoto, N. Shinya, Scr. Mater. 52, 675 (2005)

[18] K. Laha, J. Kyono, N. Shinya, Scr. Mater. 56, 915 (2007)

[19] K. Laha, J. Kyono, N. Shinya, Metall. Mater. Trans. A 43, 1187 (2012)

[20] K. Laha, J. Kyono, N. Shinya, Philos. Mag. 87, 2483 (2007)

[21] N. Shinya, J. Kyono, K. Laha, J. Intell. Mater. Syst. Struct. 17, 1127 (2006)

[22] K. Laha, J. Kyono, T. Sasaki, S. Kishimoto, N. Shinya, Metall. Mater. Trans. A 36, 399 (2005)

[23] S.K. Ghosh, Self-healing Materials: Fundamentals, Design Strategies, and Applications. (Wiley Online Library, 2009). https://www.wiley.com/en-us/9783527318292. Accessed August 2009

[24] S. He, N. van Dijk, H. Schut, E. Peekstok, S. van der Zwaag, Phys. Rev. B 81, 094103 (2010)

[25] S. He, N. van Dijk, M. Paladugu, H. Schut, J. Kohlbrecher, F. Tichelaar, S. van der Zwaag, Phys. Rev. B 82, 174111 (2010)

[26] C. Versteylen, N. van Dijk, M. Sluiter, Phys. Rev. B 96, 094105 (2017)

[27] S. Zhang, J. Kohlbrecher, F. Tichelaar, G. Langelaan, E. Brück, S. van der Zwaag, N. van Dijk, Acta Mater. 61, 7009 (2013)

[28] S. Zhang, H. Schut, J. Čížek, F. Tichelaar, E. Brück, S. van der Zwaag, N. van Dijk, J. Mater. Sci. 49, 2509 (2014)

[29] S. Zhang, G. Langelaan, J. Brouwer, W. Sloof, E. Brück, S. van der Zwaag, N. van Dijk, J. Alloys Compd. 584, 425 (2014)

[30] S. Zhang, C. Kwakernaak, W. Sloof, E. Brück, S. van der Zwaag, N. van Dijk, Adv. Eng. Mater. 17, 598 (2015)

[31] S. Zhang, C. Kwakernaak, F. Tichelaar, W. Sloof, M. Kuzmina, M. Herbig, D. Raabe, E. Brück, S. van der Zwaag, N. van Dijk, Metall. Mater. Trans. A 46, 5656 (2015)

[32] H. Fang, C. Versteylen, S. Zhang, Y. Yang, P. Cloetens, D. NganTillard, E. Brück, S. van der Zwaag, N. van Dijk, Acta Mater. 121, 352 (2016)

[33] H. Fang, N. Szymanski, C. Versteylen, P. Cloetens, C. Kwakernaak, W. Sloof, F. Tichelaar, S. Balachandran, M. Herbig, E. Brück, Acta Mater. 166, 531 (2019)

[34] D. Wei, J. Han, K. Tieu, Z. Jiang, Scr. Mater. 51, 583 (2004)

[35] D. Wei, Z. Jiang, J. Han, Comput. Mater. Sci. 69, 270 (2013)
[36] Q. Fang, J. Li, H. Luo, J. Du, B. Liu, J. Alloys Compd. 710, 281 (2017)

[37] J. Li, Q. Fang, B. Liu, Y. Liu, Y. Liu, P. Wen, Acta Mater. 95, $291(2015)$

[38] E.G. Karpov, M.V. Grankin, M. Liu, M. Ariyan, J. Mech. Phys. Solids 60, 250 (2012)

[39] M. Meraj, S. Pal, Appl. Phys. A 123, 138 (2017)

[40] C. Versteylen, N. Szymański, M. Sluiter, N. van Dijk, Philos. Mag. 98, 864 (2018)

[41] C. Versteylen, M. Sluiter, N. van Dijk, J. Mater. Sci. 53, 14758 (2018)

[42] B.S. Files, PhD thesis, Design of a Biomimetic Self-Healing Superalloy Composite, Northwestern University, 1997

[43] M.V. Manuel, PhD thesis, Design of a biomimetic self-healing alloy composite, Northwestern University, 2007

[44] M.V.M. M. C. Wright, and T. Wallace, Fatigue Resistance of Liquid-Assisted Self-Repairing Aluminum Alloys Reinforced with Shape Memory Alloys, Report by National Aeronautics and Space Administration (2013)

[45] P.K. Rohatgi, Mater. Sci. Eng. A 619, 73 (2014)

[46] J.B. Ferguson, B.F. Schultz, P.K. Rohatgi, Mater. Sci. Eng. A 620, 85 (2015)

[47] C.R. Fisher, H.B. Henderson, M.S. Kesler, P. Zhu, G.E. Bean, M.C. Wright, J.A. Newman, L.C. Brinson, O. Figueroa, M.V. Manuel, Appl. Mater. Today 13, 64 (2018)

[48] P. Zhu, Z. Cui, M.S. Kesler, J.A. Newman, M.V. Manuel, M.C. Wright, L.C. Brinson, Mech. Mater. 103, 1 (2016)

[49] O. Kovalenko, C. Brandl, L. Klinger, E. Rabkin, Adv. Sci. 4, 1700159 (2017)

[50] S.D.V.S.J.G.A.S.H.G.R. Spolenak, Adv. Mater. Technol. 6, 1800468 (2018)

[51] J. Kim, H.J. Kim, S.H. Hong, H.J. Park, Y.S. Kim, Y.J. Hwang, Y.B. Jeong, J.Y. Park, J.M. Park, B. Sarac, W.M. Wang, J. Eckert, K.B. Kim, Sci. Rep. 8, 2120 (2018)

[52] X. Zheng, Y.N. Shi, K. Lu, Mater. Sci. Eng. A 561, 52 (2013)

[53] A.M. Abdelkader, S.J. Garcia, S. van der Zwaag, Ceramics Int. 39, 3429 (2013)

[54] Z. Hsain, J.H. Pikul, Adv. Funct. Mater. 29, 1905631 (2019)

[55] H. Song, Zj Wang, Xd He, J. Duan, Sci. Rep. 7, 1 (2017)

[56] H. Song, Z.J. Wang, Mater. Sci. Eng. A 490, 1 (2008)

[57] J. Tao, B.K. Liew, J.F. Chen, N.W. Cheung, C. Hu, Microelectron. Reliab. 38, 295 (1998)

[58] W. Yao, C. Basaran, Comput. Mater. Sci. 71, 76 (2013)

[59] X.M. Luo, B. Zhang, G.P. Zhang, J. Appl. Phys. 116, 103509 (2014)

[60] A.W. Hunt, S.P. Riege, J.A. Prybyla, Appl. Phys. Lett. 70, 2541 (1997)

[61] O.G. Barbara Putz, M.J. Cordill, Mater. Res. Lett. 4, 43 (2016)

[62] G. Robert Odette, S.J. Zinkle, Structural Alloys for Nuclear Energy Applications (Elsevier, Amsterdam, 2019). https://doi. org/10.1016/C2011-0-07772-4

[63] X.M. Bai, A.F. Voter, R.G. Hoagland, M. Nastasi, B.P. Uberuaga, Science 327, 1631 (2010)

[64] V. Borovikov, X.Z. Tang, D. Perez, X.M. Bai, B.P. Uberuaga, A.F. Voter, Nucl. Fusion 53, 063001 (2013)

[65] G. Xu, M. Demkowicz, Phys. Rev. Lett. 111, 145501 (2013)

[66] X. Li, W. Liu, Y. Xu, C.S. Liu, B.C. Pan, Y. Liang, Q.F. Fang, J.L. Chen, G.N. Luo, G.H. Lu, Z. Wang, Acta Mater. 109, 115 (2016)

[67] G. Ackland, Science 327, 1587 (2010)

[68] J. Li, K. Yu, Y. Chen, M. Song, H. Wang, M. Kirk, M. Li, X. Zhang, Nano Lett. 15, 2922 (2015)

[69] K.P. So, D. Chen, A. Kushima, M. Li, S. Kim, Y. Yang, Z. Wang, J.G. Park, Y.H. Lee, R.I. Gonzalez, M. Kiwi, E.M. Bringa, L. Shao, J. Li, Nano Energy 22, 319 (2016) 
[70] L. Yang, H.Y. Li, P.W. Wang, S.Y. Wu, G.Q. Guo, B. Liao, Q.L. Guo, X.Q. Fan, P. Huang, H.B. Lou, F.M. Guo, Q.S. Zeng, T. Sun, Y. Ren, L.Y. Chen, Sci. Rep. 7, 16739 (2017)

[71] F. Xiong, M.F. Li, B. Malomo, L. Yang, Acta Mater. 182, 18 (2020)

[72] F. Xiong, Mf Li, L. Yang, Comput. Mater. Sci. 176, 109532 (2020)

[73] S. Zhang, J. Cizek, Z. Yao, M. Oleksandr, X. Kong, C. Liu, N. van Dijk, S. van der Zwaag, J. Alloys Compd. 817, 152765 (2019)

[74] S. Zhang, Z. Yao, Z. Zhang, M. Oleksandr, Appl. Surf. Sci. 504, $144383(2020)$

[75] S. Zhang, Z. Yao, Z. Zhang, M. Oleksandr, F. Chen, X. Cao, P. Zhang, N. van Dijk, S. van der Zwaag, Nucl. Instrum. Methods Phys. Res. Sect. B 463, 69 (2020)

[76] F. Zhang, P. Ju, M. Pan, D. Zhang, Y. Huang, G. Li, X. Li, Corros. Sci. 144, 74 (2018)

[77] S. Alexandridou, C. Kiparissides, J. Fransaer, J.P. Celis, Surf. Coat. Technol. 71, 267 (1995)

[78] Z.H. Xie, S. Shan, J. Mater. Sci. 53, 33755 (2018)

[79] WpLLqZ Xiuqing, X. Yanhong Guo, Int. J. Miner. Metall. Mater. 18, 377 (2011)

[80] P.E. Leser, PhD thesis, Mitigation of Crack Damage in Metallic Materials, National Aeronautics and Space Administration, 2014

[81] G.B. Yang, S.T. Chai, X.J. Xiong, S.M. Zhang, L.G. Yu, P.Y. Zhang, Trans. Nonferrous Met. Soc. China 22, 366 (2012)

[82] Y. Yang, A. Kushima, W. Han, H. Xin, J. Li, Liquid-Like Nano Lett. 18, 2492 (2018)

[83] Q. Lu, W. Xu, S. van der Zwaag, Acta Mater. 77, 310 (2014)

[84] H. Yu, W. Xu, S. van der Zwaag, Steel Res. Int. 89, 1800177 (2018)
[85] S.H. Kang, S. Lee, J.Y. Suh, H.J. Kim, Y.K. Lee, J. Alloys Compd. 805, 1217 (2019)

[86] J. Li, O.E. Shklyaev, T. Li, W. Liu, H. Shum, I. Rozen, A.C. Balazs, J. Wang, Nano Lett. 15, 7077 (2015)

[87] S.A. Ponnusami, J. Krishnasamy, S. Turteltaub, S. van der Zwaag, Int. J. Solids Struct. 134, 249 (2018)

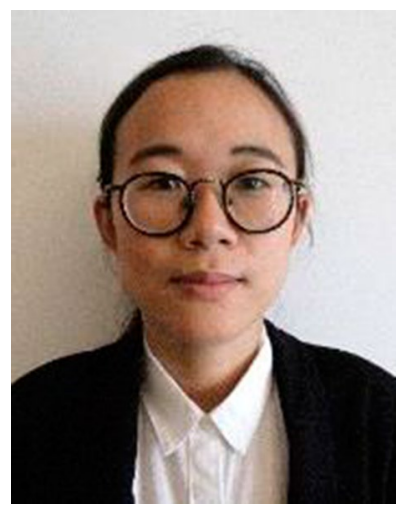

Dr. Shasha Zhang studied materials science and engineering at the Shandong University, China, to get bachelor degree and obtained her master degree in materials engineering at Shanghai Jiao Tong University, China. In 2015, she completed a PhD in applied science at the Delft University of Technology, the Netherlands. During this period, she performed innovative study on self-healing in steels. She is currently appointed as associate researcher at the Nanjing University of Aeronautics and Astronautics, China. Her main fields of expertise are self-healing metals, nuclear materials, metallurgy and additive manufacturing. 